\title{
A world-wide education in crystallography
}

Amy A. Sarjeant ${ }^{1}$, Allen G. Oliver ${ }^{2}$, Charlotte L. Stern ${ }^{3}$, Suzanna C. Ward ${ }^{4}$, Peter A. Wood ${ }^{4}$

${ }^{1}$ The Cambridge Crystallographic Data Centre, Piscataway, United States, ${ }^{2}$ The University of Notre Dame, Notre Dame, United States, ${ }^{3}$ Northwestern University, Evanston, United States, ${ }^{4}$ The Cambridge Crystallographic Data Centre, Cambridge, United Kingdom

E-mail: sarjeant@ccdc.cam.ac.uk

Every chemist and biochemist requires an in-depth understanding of the compounds and proteins with which they work. Arguably the best way to understand chemical reactions and biological interactions is through visualization of the products, reactants and transition states along the way. And the best way to achieve such an understanding is through crystallographic structure determination. How is it then, that so few students of chemistry and biochemistry receive an education in the science of crystallography? The technique lags behind other analytical methods, such as NMR and Mass Spectrometry, which are well established in standard degree programs. As crystallography is not included in routine coursework, it is left to crystallographers themselves to provide this education through other venues.

There exists today a number of well-established schools devoted to training students in the art of crystallography including those sponsored by the American Crystallographic Association and the British Crystallographic Association, and the International School of Crystallography at Erice, to name but a few. This talk will feature some experiences in teaching the next generation of crystallographers from these schools, including some attempts at distance-teaching to reach the global crystallographic community.

Keywords: education, teaching 